\title{
Dos metáforas esenciales
}

\section{Two essential metaphors}

\author{
Antonio C. Gutiérrez-Piñeres PhD Sc. \\ Tecnológica de Bolívar, Cartagena-Colombia \\ mail.acgutierrez@unitecnologica.edu.co
}

... la especulación salió de manos de los topos y fue entregada como un deber, más que como una tarea, a los verdaderos pensadores, los únicos verdaderos, a los hombres de cultura general y

ardiente imaginación

E. A. Poe, en Eureka

En una "sentencia" el poeta romántico Friedrich Hölderlin declara que "lleno está de méritos el Hombre; mas no por ellos; por la Poesía ha hecho de esta Tierra su morada”. En gran medida, el tecnicismo en que nos ha hecho caer el galopante avance de las ciencias y la necesidad de especialización en sus diferentes tópicos, podría hacernos pensar ingenuamente que el gran Hölderlin, en la idea anterior, restó "méritos" al conocimiento científico y a sus aplicaciones que deben mejorar nuestra calidad de vida, y elevó a su máxima potencia la importancia del "quehacer" del poeta. Un ejercicio más integrador es el que me propongo en el presente esbozo para un plan.

De la conferencia, La Metáfora, ${ }^{1}$ ofrecida por Borges, se entiende que es posible seleccionar un mínimo número de metáforas "modelo" a partir de las cuales podemos derivar una variedad casi infinita de metáforas que han perdurado y renacido en diferentes tiempos, ámbitos y lugares "... así que podríamos hablar de ellas como ecuaciones". No discutiré aquí si el poeta, en el momento en que las concibió, fue dotado o no de la magnificencia que confiere la inspiración; lo que si defiendo es que creo que resulta acertado suponer que cada una de ellas nació en una suerte de ámbito, en el cual el poeta (aunque no se supo) estaba dotado de la percepción que presupone todo acto de creación en las ciencias naturales. Del mismo modo, en que durante su acto de creación el científico postula, corrige y pule, no sin pensar en simetrías y estética.

La primera metáfora modelo, a la que Borges alude en su conferencia, es la que sugiere la comparación entre ojos y estrellas, presentada en tres variaciones conmemorables. Una, procedente de la Antología griega, "Desearía ser la noche para mirar tu sueño con mil ojos". Otra, "las estrellas miran hacia abajo". Y la tercera procedente de un poema de Chesterton "pero no envejeceré hasta ver surgir la enorme noche, / nube que es más grande que el mundo, / monstruo hecho de ojos." En las tres metáforas anteriores, claramente podemos notar un aspecto relativo en el que el poeta a veces se ubica en las estrellas para mi-

Received January 2011 / Accepted May 2011 
rar tu sueño, en la otra el poeta se ubica en otro marco ... hasta ver surgir la enorme noche, o en ninguno de los dos marcos de referencia miran hacia abajo. En cada caso, de todos modos, está segura la posición del poeta como observador que ha sido siempre del cielo general, en un juego estético de Kepler o de Copérnico del movimiento estelar.

Alguna vez, a la pregunta formulada a San Agustín, ¿Qué es el tiempo?, éste respondió: conozco la respuesta en la medida en que me sea dado no responderla. Y su "respuesta" es bastante justificada, pues sin exageración alguna, la respuesta a esa pregunta constituye el cuerpo central de la Metafísica. La segunda metáfora modelo constituye una bella salida al dilema: la comparación entre el tiempo, sustancias de las que están hechos los seres, y el fluir, como el de un río. Una variación la presenta Tennyson: «El fluir del tiempo en medio de la noche". Otra es de Heráclito: "Nadie baja dos veces al mismo río". Y otra, que reafirma la idea de que estamos hechos de tiempo y expuesta por Don Jorge Manrique en sus Coplas: "Nuestras vidas son los ríos / que van a dar al mar / que es el morir". Todos hemos construido, al menos tácitamente, estas metáforas o sus variaciones mientras estudiamos los conceptos de flujo de un fluido, líneas y flujo del campo eléctrico. Y de paso recordamos la simple idea de divergencia y su interpretación física en términos de fluidos y leyes de conservación.

Jorge Luis Borges; Arte Poética, Seis Conferencias. Crítica, 2001

De la famosa serie de "Los Girasoles" es fama que Vincent van Gogh, en su proceso de creación, quiso "atrapar" la luz. Esta suerte de ensueño no era nuevo ya que había sido perseguido también por Leonardo da Vinci (y además, todos tenemos las mismas ensoñaciones con intensidades diferentes). Johann Wolfgang von Goethe elaboró una
"Teoría del Color", aunque no fue bien recibida por los intelectuales de su época, se sabe hoy que muchos filósofos y físicos, incluyendo a Arthur Schopenhauer, Kurt Gódel, Werner Heisenberg, Ludwig Wittgenstein, y Hermann von Helmholtz, han afirmado que Goethe estuvo en lo cierto en su teoría. Esas mágicas búsquedas del conocimiento de la luz y el color han sido aterrizadas siempre en una comparación fantástica, que no es del todo ajena en la memoria de los hombres y que constituye el tercer modelo de metáfora a las que Borges alude en su conferencia. La comparación entre la mujer y la flor. La luz, la mujer y la flor, la luz y la mujer, la flor y el tiempo. Están presentes en una sutil insinuación confesa de la alegría del recibimiento de un sensual premio: "anoche a la media noche Marlene me dio una flor / era del color de un Toche / fue como prueba de amor", en un canto de Juancho Polo, de quien recuerdo una boca sin dientes que canta alegre. "La mujer y la primavera / ay son dos cosas que se parecen / La mujer huele cuando esta nueva / La primavera cuando florece»: el gran Alejo Durán también compara la mujer con la flor y el tiempo. Y con más tino y belleza Calixto Ochoa dice, con la nostalgia que sugiere el dolor a causa del desamor: "Yo tenía mi Lirio rojo bien adornao / con una rosita blanca muy aparente / pero se metió el verano y lo ha marchitao/por eso vivo llorando mi mala suerte."

Creo que a P. Gutiercant fue a quien le escuché decir que "El número de dimensiones y la manera en que fluye el tiempo en el que transcurren los sucesos durante el sueño son diferentes a los de la vigilia, de modo que a menos que sepamos cuál es la "Ley de Transformación" entre un estado y otro, no recordaremos con exactitud, o no recordaremos, o no entenderemos lo transcurrido durante el sueño si pensamos desde la vigilia $y$, viceversa". En esas líneas se entrelaza una intersección indisoluble que impide conocer cuál de los dos es "más o menos real". Una metáfora que precede la anterior comparación entre sueño y 
vida, y que la supera en profundidad y belleza, es la presentada por Chuang Tzu, quien dijo que soñó que era una mariposa y al despertar no sabía si era un hombre que había soñado ser una mariposa, o una mariposa que ahora soñaba ser un hombre. En la hermosa fábula de la Alicia de Caroll también se nota esta magia parcial cuando alguien pide a Alicia no hacer despertar al Rey, pues se acabaría la historia. La metáfora que compara sueño con vida es la cuarta a la que Borges alude en su conferencia.

Ahora someto a consideración de ustedes en las propias líneas de Borges una metáfora que proviene de la poesía persa (quizá de Ornar Hayyam) en la que se habla de la luna llamándola "El espejo del tiempo". En palabras de Borges se lee: Me figuro que desde el punto de vista de la astronomía, la idea de que la luna sea un espejo sería apropiada, pero esto es más bien irrelevante desde un punto de vista poético. Si la luna es o no realmente un espejo carece de la menor importancia, puesto que la poesía habla a la imaginación. Contemplemos la luna como espejo del tiempo. Creo que es una metáfora excelente: en primer lugar, porque la idea de espejo nos transmite la luminosidad y fragilidad de la luna, $y$, en segundo lugar, porque la idea de tiempo nos recuerda de repente que la luna clarísima que vemos es muy antigua, está llena de poesía y mitología, y es tan vieja como el tiempo. A este propósito, yo agregaría además que la metáfora incluye el proceso de expansión (o contracción) del universo: es un espejo del tiempo en la medida en que su cercanía o su lejanía nos comunicaría cuanto tiempo ha pasado o tendría que pasar para que estuviese "ahí".

Quiero ahora presentar dos metáforas modernas. Definen, por decirlo así, a la física moderna, dado que sus esencias postulan el nacimiento de nuevas maneras de observar e interpretar la naturaleza. Las llamaré Metáfora del Gato de Schrödinger y la Metáfora de la Equivalencia.
La esencia de la primera se deriva del famoso experimento mental que el Físico austríaco Erwin Schrödinger formuló en 1935: Supóngase que se dispone de un sistema constituido por una caja cerrada en cuyo interior se encuentra un gato y un dispositivo subatómico radiactivo con un $50 \%$ de probabilidades de activarse; si este se activa, después de un tiempo dado el gato muere.

Ante la pregunta ¿Antes de abrir la caja el gato estará vivo o muerto? Ssin atender a reglas probabilísticas, uno se sentiría tentado a afirmar que el gato está vivo o está muerto. Sin embargo, atendiendo a tales leyes, el gato subsiste en ambos estados y entonces estará vivo y muerto. Al momento de abrir la caja el observador perturbará al sistema, confiriéndole la posibilidad de vivir o morir (es decir, ante la respuesta a nuestra pregunta obtenemos una nueva inquietud, como sucede en la fábula de Proteo, quien al momento de recibir una pregunta cambia de forma para escabullirse de su interlocutor). Esta es pues una sutil metáfora en la que conviven el ser y el no ser. Una especie de gato Pedro Páramo. Me pregunto cómo habrían cambiado los soliloquios de Hamlet si Shakespeare hubiera recibido estas noticias.

Según Albert Einstein "las leyes de la naturaleza deben expresarse de modo que sea imposible distinguir entre un campo gravitatorio y un sistema referencial acelerado." De este modo, es imposible distinguir entre masa gravitacional y masa inercial. Este enunciado conocido como Principio de Equivalencia constituye el fundamento conceptual de una teoría moderna de la gravitación. De acuerdo con él, además, las propiedades geométricas del espacio no son independientes sino que están condicionadas por la materia. Lo propongo como una metáfora porque, su belleza nos sugiere imágenes, imaginación. Nos permite pensar que las paralelas que nunca se cortan, según la geometría de Euclides, y que el postulado pitagórico según el cual la suma de los ángulos internos de un triángulo es $180^{\circ}$ son conjeturas sólo posibles en un universo no 
afectado localmente por la presencia de materia. Nos permite, según algunas interpretaciones, ver la gota que cae en el hidrante de Rulfo, como viajera en un fluido de superficies curvas.

Creo, a manera de conclusión, de este ejercicio, que entonces es imposible suponer al poeta que desliga álgebra y luna, la velocidad y Aquiles. Y al científico destituido de lo que "la primavera hace con los cerezos". Ahora bien, el ejercicio de imbricar metáforas, de obtener una tercera metáfora a partir de dos anteriores, creo que es un ejercicio no menos valioso. Con el tiempo tendremos una nueva bella metáfora en la que el gato de Schrödinger se sabrá vivo y muerto en una variedad riemanniana. Me pregunto quién llegará primero a la metáfora ¿el físico o el poeta?

THE AUTHOR

ANTONIO C GUTIÉRREZ-PIÑERES es doctor en Ciencias Naturales (Física) y Magister en Física de la Universidad Industrial de Santander. Actualmente es docente de tiempo completo de la Universidad Tecnológica de Bolívar, Cartagena. Ha publicado artículos sobre física en el tema de Relatividad General y sobre Literatura y Física en revistas científicas nacionales e internacionales. 